\title{
Power Injection Method-based Evaluation of the Effect of Binding Technique on the Coupling Loss Factors and Damping Loss Factors in Statistical Energy Ana- lysis Simulations
}

\author{
Marcell Ferenc Treszkai (0000-0002-8910-4812)를 , Alexander Peiffer (0000-0002-8654-8266)², Daniel Feszty (0000- \\ 0001-5876-9005)1 \\ ${ }_{1}^{1}$ Audi Hungaria Faculty of Automotive Engineering, Department of Whole Vehicle Engineering, Széchenyi István \\ University. Egyetem tér 1, H-9026 Győr. Hungary. E-mail: treszkai.marcell.ferenc@ga.sze.hu, feszty.da- \\ niel@sze.hu \\ 2Audi AG, I/XX-99, 85045 Ingolstadt, Germany, E-mail: alexander.peiffer@audi.de
}

\begin{abstract}
Measurement results on the Damping Loss Factor (DLF) and Coupling Loss Factor (CLF) between two steel plates is presented for 19 different junction types. The junctions involve joining technologies, such as line welding, point welding, bolting, riveting, gluing or their combinations, and with varying spacing between the junction points and the angle between the plates. From the measurement results, the DLF and CLF values were calculated by the Power Injection Method for the purposes of being applied in Statistical Energy Analysis simulations. Four excitations were applied at each subsystem by impact hammer, while the response was recorded at sixteen response points at each subsystem. The measured CLF values were compared to each other from various aspects. Data were compared to the results obtained from SEA simulations by using the built-in analytical formulas. In general, good comparison was observed, although the results appeared to be somewhat dependent on the frequency band. Finally, it was examined whether replacing the DLF values with data obtained for an uncoupled flat plate, as well replacing the CLF values with data from analytical formulas leads to acceptable accuracy of the simulation results.
\end{abstract}

Keywords: Statistical Energy Analysis, Damping Loss Factor, Coupling Loss Factor, Junction types, Vibration

\section{Introduction}

Nowadays, virtual analysis is essential for the Noise, Vibration, and Harshness (NVH) development of vehicles. There are several possible approaches to solve a vibroacoustic problem. Statistical Energy Analysis (SEA) is one of the powerful methods to solve complex vibro-acoustical systems fast. However, since SEA assumes high modal density, the method works best in the high-frequency range, where the structural response can be statistically described [1]. SEA has different branches, such as experimental, analytical and virtual. In this study, the experimental SEA is used mainly, where the key SEA parameters, such as the Damping Loss Factor (DLF) and the Coupling Loss Factor (CLF) are derived from measurements. These two parameters play an important role in the energy equilibrium of coupled systems. DLF represents the energy dissipation of the subsystem, while the CLF the energy exchange through the junction. There are several parameters which influences the structural damping of the system [2], in addition the microscopic structure has also impact to it [3]. Numerous methods exist for obtaining the CLF, such as the modal appro- ach [1], the energy ratio method [4] or the Power Injection Method (PIM) [5-7]. Several papers deal with the experimental determination of CLFs. Sablik [8] measured the transmission coefficient and CLF for beams in L-shape joints. Mandale, et. al [9] measured L-shape structures with different plate materials, such as steel, copper, acrylic, etc. connected by screwed and bolted junctions. They used the energy level difference method to calculate the CLF values. Mandale, et. al [10] in a later study investigated L-shaped structures with different materials and various junction types, such as screwed, bolted and riveted junctions with different joining lengths. The effect of the tightening torque on bolted junction is also investigated. Jintao and Meiping [2] improved an energy ratio method to estimate CLFs for three shell cylinders. Le Bot, et al. [11] examined three rectangular plates with random resonators, the coupling parameter is estimated by SEA equations and compared to a semi-analytical method. Patil and Manik [12] performed a sensitivity analysis of two right angle coupled plates connected via welded and bolted joints. Panuszka, et al. [13] measured the SEA parameters experimentally and compared the results to analytical formulas. The test cases 
were L-shape structures with different type of junctions and different thickness ratios of the plates. The DLF was estimated from the reverberation time, while the CLF was obtained from the power balance equation. Bosmans, et al. [14] examined theoretically an L-junction with varying plate dimensions and varying orthotropic stiffness of the plate material. Cuschieri and Sun [15] determined the dissipation and coupling loss factors for a rotating machinery structure, based on measurements of the energy ratios between the subsystems. Wester and Mace [16] investigated two edge-coupled simply supported, rectangular plates from coupling strength and modal overlap point of view, while Wöhle, et al. [17] calculated the CLFs at rectangular slab junctions, by assuming springs at the coupling points and the possible energy losses. In a subsequent publication, the same authors have also examined the structure-borne sound transmission created by forced bending wave [18]. While these works provide valuable experimental data for CLF for various junction types, there is a lack of comprehensive comparison of the experimental data and analytical data for a wide range of junction types typical of vehicle structures in the mid-frequency (400$1000 \mathrm{~Hz}$ ) range. Such comparison is important to increase the confidence in the analytical data, so that SEA simulations can be used in the early phases of vehicle development without the need of conducting experiments.

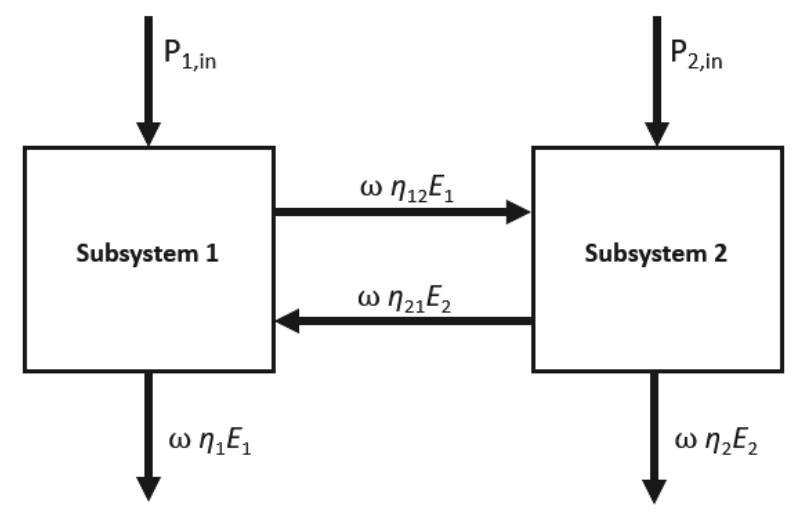

Fig. 1 Energy balance between two subsystems

Therefore, the main purpose of this work is to investigate the effect of the joint type on the CLF values and to compare experimental and SEA simulation results. Five joint types - typical of vehicle structures - in

$$
\omega\left[\begin{array}{ccc}
\eta_{11} & \cdots & -\eta_{n 1} \\
\vdots & \ddots & \vdots \\
-\eta_{1 n} & \cdots & \eta_{n n}
\end{array}\right]\left[\begin{array}{c}
E_{11} \\
\vdots \\
E_{1 n}
\end{array}\right.
$$

Where:

$\eta_{11}$ and $\eta_{n n}$ are the Damping Loss Factor of the $1^{\text {th }}$ and $n^{t h}$ subsystem, respectively [-],

$\eta_{1 n}$ and $\eta_{n 1}$ are the Coupling Loss Factors, which
19 different configurations are investigated. The investigation focuses on the mid-frequency range (400 $1000 \mathrm{~Hz}$ ), because this is the most challenging in NVH [19]. The power injection method is used to calculate the loss matrix, then the CLF values of the different junctions are compared to each other. Two levels of investigations are applied to check the accuracy of the analytical formulas. First, the DLFs from the experimental PIM are kept, while the simulation software calculates the CLFs from analytical equations. Second: the DLFs are kept constant while the CLFs from analytical equations are applied. Therewith, it is possible to examine how the different junction types can be taken into account during the simulation through analytical CLF data, and what accuracy can be achieved if no measurement data is available from the structure.

\section{Power Injection Method}

The Loss Matrix can be obtained through the Power Injection Method. In this method, one subsystem is excited with the injected power recorded, while all other subsystem's (response) energies are measured. Then, the next subsystem is excited, and the total energy of the other subsystems is measured and so on.

Consider a single subsystem, e.g. a flat plate. The injected power equals with the power loss, as the following equation shows:

$$
P_{\text {in }}=\omega E \boldsymbol{\eta}[\mathrm{W}],
$$

Where:

$P_{\text {in }}$ is the injected power [W],

$\omega$ is the angular frequency $[\mathrm{rad} / \mathrm{s}]$,

$E$ is the stored vibrational energy of the subsystem [Nm],

$\eta$ is the Damping Loss Factor (DLF) [-].

For coupled structures, at subsystem connection the energy conservation can be written as:

$$
\boldsymbol{P}_{i, \text { in }}=\boldsymbol{P}_{i, \text { diss }}+\sum_{j=1, \neq i}^{k} \boldsymbol{P}_{i j}[\mathrm{~W}],
$$

Where: (1),

$P_{i, d i s s}$ is the dissipated power and equals with Eq.

$P_{i j}$ is the power dissipation at the connections.

When $n$ subsystems are connected to each other, then the Power Injection Method equation can be written in matrix form in the following way:

$$
\left.\begin{array}{cc}
\cdots & E_{n 1} \\
\ddots & \vdots \\
\cdots & E_{n n}
\end{array}\right]=\left[\begin{array}{ccc}
P_{1} & \cdots & 0 \\
\vdots & \ddots & \vdots \\
0 & \cdots & P_{n}
\end{array}\right][\mathrm{W}]
$$

represent the energy loss at the junctions [-].

The present study deals with two plates connected along a line junction, which can be represented as a 
two-subsystems SEA model. Fig. 1 illustrates the power flow for a two subsystems model.

$$
\left(\begin{array}{cc}
P_{1} & 0 \\
0 & P_{2}
\end{array}\right)=\omega\left(\begin{array}{c}
\eta_{1}+\eta_{12} \\
-\eta_{12}
\end{array}\right.
$$

The reciprocity relation is:

$$
n_{1} \eta_{12}=n_{2} \eta_{21}[-]
$$

where:

$n_{1}, n_{2}$ are the modal densities of the subsystem 1 and 2 , respectively [modes $/ \mathrm{Hz}]$.

The modal density describes the number of resonance modes of the given subsystem over the considered frequency band. From experiment, the input power can be obtained from [20]:

$$
\begin{gathered}
\boldsymbol{P}_{\text {in }}=\boldsymbol{F}^{2} \operatorname{Re}\{\boldsymbol{Y}(\omega)\}[\mathrm{W}], \\
\boldsymbol{Y}(\omega)=\frac{v}{\boldsymbol{F}}\left[\frac{\mathrm{m}}{\mathrm{s}}\right],
\end{gathered}
$$

Where:

$F$ is the excitation force $[\mathrm{N}]$, $v$ is the velocity response at the driving point $[\mathrm{m} / \mathrm{s}]$, $Y(\omega)$ is the driving point mobility $[(\mathrm{m} / \mathrm{s}) / \mathrm{N}]$.

The subsystem vibration energy, according to Ref. 18 is:

$$
E=m<v^{2}>[\mathrm{Nm}],
$$

Where:

$E$ is the kinetic energy of the subsystem $[\mathrm{Nm}]$, $m$ is the mass of the subsystem $[\mathrm{kg}]$,
The energy balance equations of the two subsystems can then be expressed as:

$$
\left.\begin{array}{c}
-\eta_{21} \\
\eta_{2}+\eta_{21}
\end{array}\right)\left(\begin{array}{ll}
E_{11} & E_{12} \\
E_{21} & E_{22}
\end{array}\right)[\mathrm{W}]
$$

$\left\langle v^{2}\right\rangle$ is the spatially averaged squared vibration velocity of the subsystem $[\mathrm{m} / \mathrm{s}]$.

\section{Test cases}

Five type of joints typical of vehicle chassis structures - line welded, point welded, riveted, bolted, and glued.- are investigated in 19 different combinations (see Tab. 1). The point-like junctions are examined in two different point patterns. There are special junction types, such as the pure bended case, where obviously no joining technology was necessary between the subsystems. This case represented the "perfect" junction and served for comparison purposes. In addition, mixed junctions, such as combined gluing and bolting, are also examined, since this is typical for the vehicle industry. Not just the different junction types are measured, but also that how the angle of the connected plates affect the CLF values. For this reason, $90^{\circ}$ and $60^{\circ}$ connection angles are considered too. All the structures were made out of $2 \mathrm{~mm}$ thick cold rolled steel material without any surface treatment. They were cut to size via laser. The material porperty of the base S355 steel plate is the following: density of 7850 $\mathrm{kg} / \mathrm{m}^{3}$, Young's modulus of $200 \mathrm{GPa}$ and Poisson's ratio $=0.3$. Tab. 1 shows all the test cases in detail.

One interesting investigation was the bended structure, because in this case, no extra junction between the two subsystems was present, i.e. this structure was essentially a single bended plate (Fig. 2).

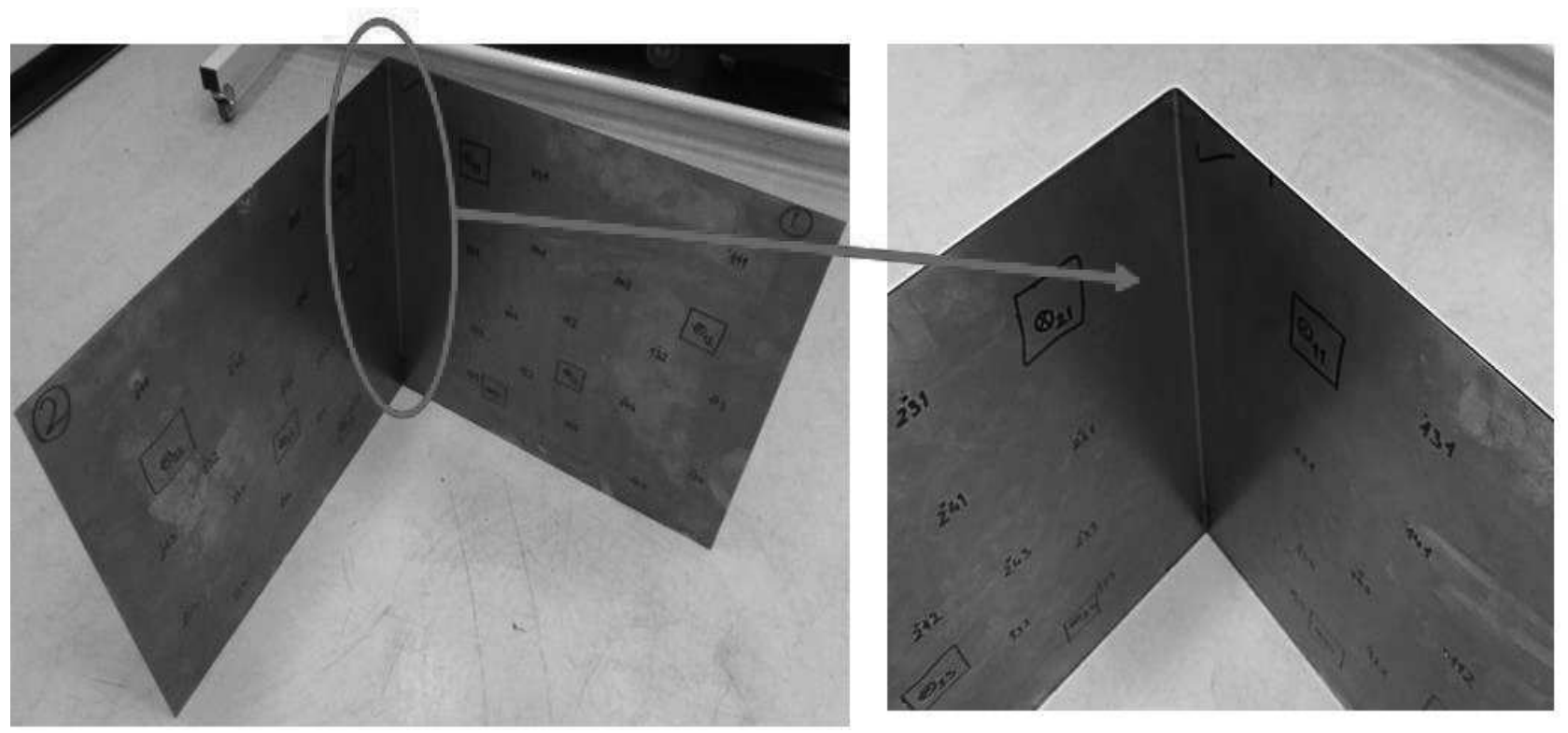

Fig. 2 Bended structure, it contains no junction. It represents the perfect connection. 
Tab. 1The measured structures and their descriptions

\begin{tabular}{|c|c|c|c|}
\hline $\begin{array}{l}\text { Number } \\
\text { of the } \\
\text { case }\end{array}$ & $\begin{array}{l}\text { Name - Type of } \\
\text { the junction }\end{array}$ & $\begin{array}{l}\text { Connection } \\
\text { angle of the } \\
\text { plates }\end{array}$ & Description of the structure \\
\hline 1 & Bended & $90^{\circ}$ & No junction, only one plate bended \\
\hline 2 & Line welded & $90^{\circ}$ & Tungsten Inert Gas welding along the line, with $20 \mathrm{~mm}$ overlap \\
\hline 3 & Point welded & $90^{\circ}$ & $\begin{array}{l}\text { Manual point welding machine, } \sim 5 \mathrm{~mm} \text { points, } 90 \mathrm{~mm} \text { spacing, } \\
\text { in all } 5 \text { connection points, } 20 \mathrm{~mm} \text { overlap }\end{array}$ \\
\hline 4 & Point welded & $90^{\circ}$ & $\begin{array}{l}\text { Manual point welding machine, } \sim 5 \mathrm{~mm} \text { points, } 50 \mathrm{~mm} \text { spacing, } \\
\text { in all } 10 \text { connection points, } 20 \mathrm{~mm} \text { overlap }\end{array}$ \\
\hline 5 & Bolted & $90^{\circ}$ & $\begin{array}{c}\text { M5 bolts, } 90 \mathrm{~mm} \text { spacing, in all } 5 \text { connection points, } 30 \mathrm{~mm} \\
\text { overlap }\end{array}$ \\
\hline 6 & Bolted & $90^{\circ}$ & $\begin{array}{c}\text { M5 bolts, } 50 \mathrm{~mm} \text { spacing, in all } 10 \text { connection points, } 30 \mathrm{~mm} \\
\text { overlap }\end{array}$ \\
\hline 7 & Riveted & $90^{\circ}$ & $\begin{array}{c}\text { Rivets } \mathrm{d}=4.8 \mathrm{~mm}, 90 \mathrm{~mm} \text { spacing, in all } 5 \text { connection points, } 30 \\
\text { mm overlap }\end{array}$ \\
\hline 8 & Superglued & $90^{\circ}$ & $\begin{array}{c}\text { Superglue (Loctite 454), } 30 \mathrm{~mm} \text { overlap, pressure and drying: } 4 \\
\mathrm{hrs}\end{array}$ \\
\hline 9 & Realistic - Glued & $90^{\circ}$ & $\begin{array}{l}\text { Vehicle industry like glue (Loctite 3450), } 30 \mathrm{~mm} \text { overlap, pres- } \\
\text { sure and drying: } 12 \mathrm{hrs}\end{array}$ \\
\hline 10 & Superglued & $90^{\circ}$ & $\begin{array}{c}\text { Superglue (Loctite } 454), 30 \mathrm{~mm} \text { overlap, pressure and drying: } 4 \\
\text { hrs, thickness of Plate 2: } 1.5 \mathrm{~mm}\end{array}$ \\
\hline 11 & Superglued & $90^{\circ}$ & $\begin{array}{c}\text { Superglue (Loctite } 454 \text { ), } 30 \mathrm{~mm} \text { overlap, pressure and drying: } 4 \\
\text { hrs, thickness of Plate 2: } 2.5 \mathrm{~mm}\end{array}$ \\
\hline 12 & $\begin{array}{c}\text { Riveted }+ \text { super- } \\
\text { glued }\end{array}$ & $90^{\circ}$ & $\begin{array}{c}\text { Rivets } \mathrm{d}=4.8 \mathrm{~mm}, 90 \mathrm{~mm} \text { spacing and Loctite } 454 \text {, pressure: the } \\
\text { rivets, } 30 \mathrm{~mm} \text { overlap }\end{array}$ \\
\hline 13 & $\begin{array}{l}\text { Bolted + super- } \\
\text { glued }\end{array}$ & $90^{\circ}$ & $\begin{array}{l}\text { M5 bolts, } 50 \mathrm{~mm} \text { spacing and Loctite } 454 \text {, pressure: the bolts, } 30 \\
\mathrm{~mm} \text { overlap }\end{array}$ \\
\hline 14 & Point welded & $60^{\circ}$ & $\begin{array}{l}\text { Manual point welding machine, } \sim 5 \mathrm{~mm} \text { points, } 90 \mathrm{~mm} \text { spacing, } \\
\text { in all } 5 \text { connection points, } 20 \mathrm{~mm} \text { overlap }\end{array}$ \\
\hline 15 & Point welded & $60^{\circ}$ & $\begin{array}{l}\text { Manual point welding machine, } \sim 5 \mathrm{~mm} \text { points, } 50 \mathrm{~mm} \text { spacing, } \\
\text { in all } 10 \text { connection points, } 20 \mathrm{~mm} \text { overlap }\end{array}$ \\
\hline 16 & Bolted & $60^{\circ}$ & $\begin{array}{l}\text { M5 bolts, } 90 \mathrm{~mm} \text { spacing, in all } 5 \text { connection points, } 30 \mathrm{~mm} \\
\text { overlap }\end{array}$ \\
\hline 17 & Bolted & $60^{\circ}$ & $\begin{array}{c}\text { M5 bolts, } 50 \mathrm{~mm} \text { spacing, in all } 10 \text { connection points, } 30 \mathrm{~mm} \\
\text { overlap }\end{array}$ \\
\hline 18 & Riveted & $60^{\circ}$ & $\begin{array}{c}\text { Rivets } \mathrm{d}=4.8 \mathrm{~mm}, 90 \mathrm{~mm} \text { spacing, in all } 5 \text { connection points, } 30 \\
\mathrm{~mm} \text { overlap }\end{array}$ \\
\hline 19 & Superglued & $60^{\circ}$ & $\begin{array}{c}\text { Superglue (Loctite 454), } 30 \mathrm{~mm} \text { overlap, pressure and drying: } 4 \\
\text { hrs }\end{array}$ \\
\hline
\end{tabular}
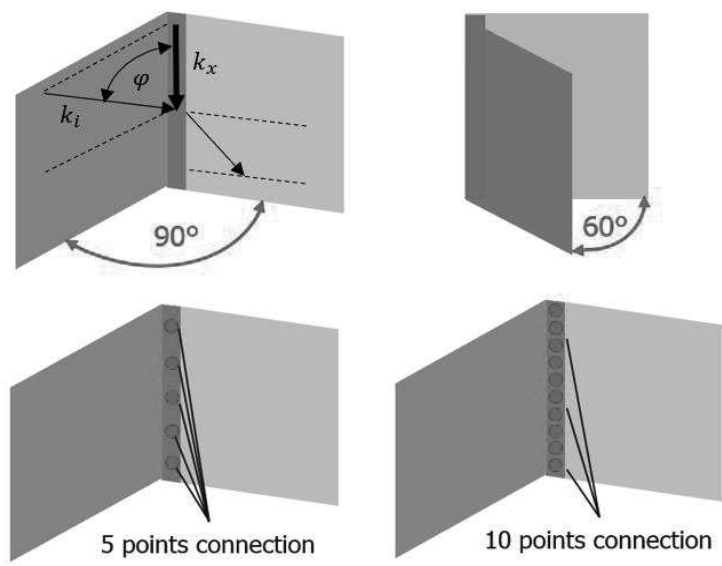

Fig. 3 Two types of connection angles and point densities
As Tab. 1. shows, not only the type of the junction is changed but also the density of the joining points in the case of the bolted and point welded structures. Two different glues are examined, a) the Loctite 454, which is a superglue with $20.9 \mathrm{~N} / \mathrm{mm}^{2}$ shear strength [21]; and b) the Loctite 3450, which is similar to the ones used in car structures with $25 \mathrm{~N} / \mathrm{mm}^{2}$ shear strength [22]. Moreover, the bending angle is also changed. Fig. 3 illustrates these parameters.

\section{Experimental setup for estimating the loss matrix}

The main goal of the experiment was to ensure repeatability and comparability of the different connection types. Thus, size and material of the test 
structures are the same, only the type of the junction is changed. The considered structures consist of two rectangular steel plates. Plate 1 with size 650 × 550 × 2 $\mathrm{mm}$ and plate 2 with $655 \times 550 \times 2 \mathrm{~mm}$. Fig. 4 shows the background of the experiment, illustrating that four excitations/plate and sixteen response points/plate are applied. At once only four response points are measured per plate to minimize the mass added to the plates. Fig. 5 illustrates the connection of the plates and the difference between plates 1 and 2, which will have quite significant effect, as will be seen later.

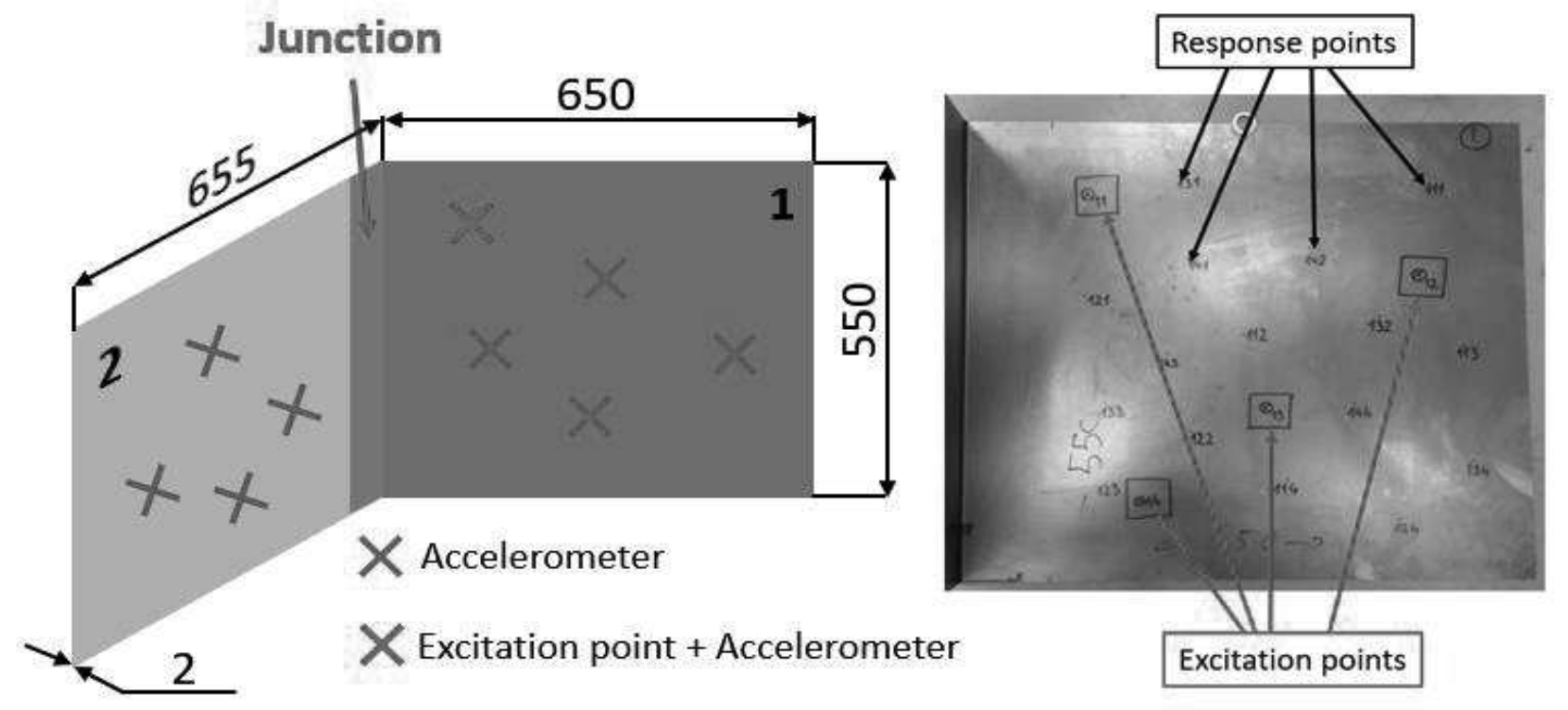

Fig. 4 Illustration of the measurement concept (left) and the location of the excitation and response points (right)

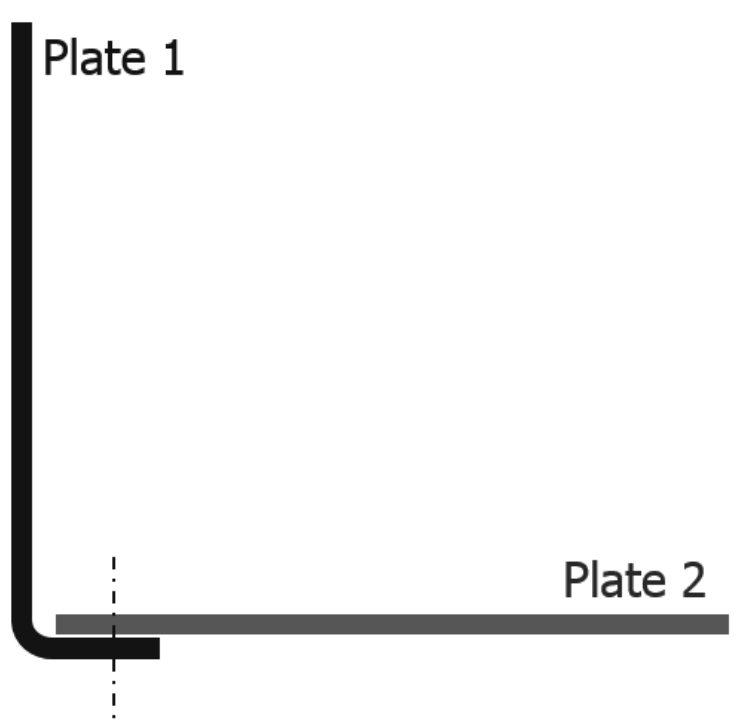

Fig. 5 Detail of the plate's connection: Plate 1 is overlapped with Plate 2 in a $90^{\circ}$ and $60^{\circ}$ bend, depending on the angle of the connection. This connection will be seen at all structures, except the bended structure, since in that case there is no junction.

The responses on both plates are measured at 12 points, with only four accelerometers/plate at once. This is done to reduce the added mass to the subsystems. An additional accelerometer is placed on the excited plate, because of the driving point measurement at the excitation point. The response is measured by lightweight ICP piezoelectric accelerometers from
$B \& K$. The plate is excited at four points on each plate, performed by an impact hammer. The impact hammer was PCB Piezotronics with a hard rubber head. The excitation and response points were at the same locations on every measured structure. Free-free boundary conditions are used during the experiment. Although the investigation focused on the mid-frequency range $(400-1000 \mathrm{~Hz})$, the measured frequency range was between 178 and $1778 \mathrm{~Hz}$, in order to cover the investigated frequency range properly. The frequency resolution was $0.07 \mathrm{~Hz}$ during the measurements.

\section{Coupling loss factors of different joint ty- pes}

The results of the SEA simulations for complex structures depend on the CLFs. In simple cases these can be calculated analytically. However, in more complex cases or when the connection contains different junction types, such as riveted, glued, or welded joints, the analytical determination might not be possible. Therefore, in such cases experiments are necessary to obtain them accurately. In this section, the coupling loss factors of the different junction types are compared to each other.

Firstly, the modal parameters of the structures are introduced. It is important to note that these test cases do not necessarily constitute a proper SEA subsystems in the examined frequency range $(200 \mathrm{~Hz}$ and higher). Fig. 6 shows the modes in the bands as well as the modal density of the bended structure. 
Modes In Band

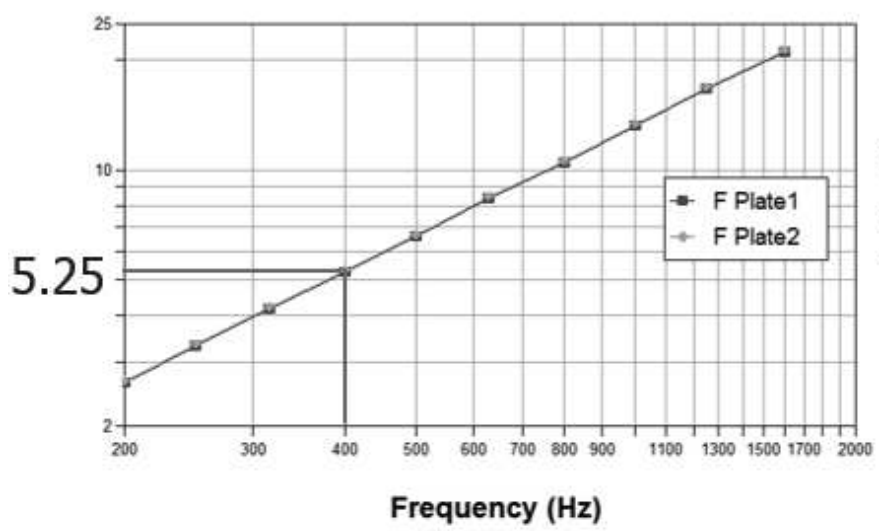

Modal Density

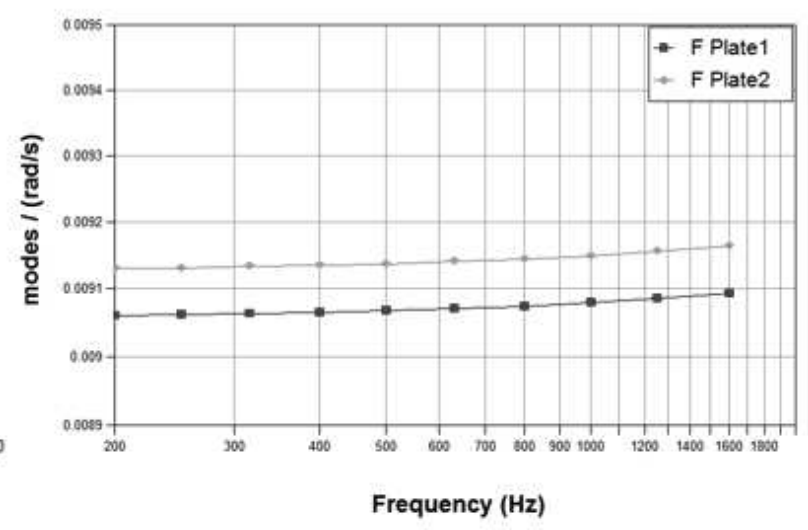

Fig. 6 Modes in Band and Modal Density of the Bended structure

As can be seen, at the $400 \mathrm{~Hz}$ third octave band, there are around 5.25 modes, while the modal density is around 0.001 . Note that SEA normally assumes at least 3 modes per third octave band [1].

Next, the reciprocity relationship is examined, as illustrated in Fig. 7 This represents the coupling loss factor values from Plate 1 to Plate 2 and vice versa. The coupling must be conservative between the subsystems [1],[25]. Note that the modal densities of the

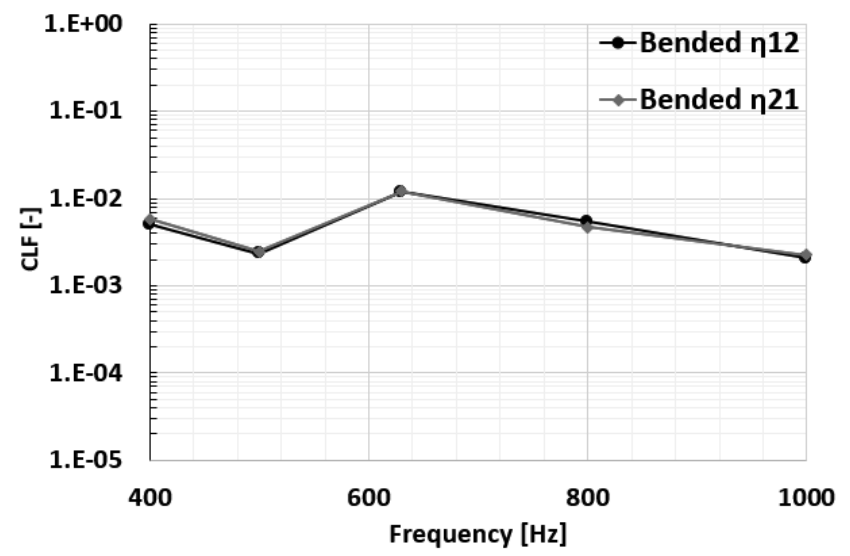

two subsystems are very similar, because of the close similarity in the size and shape of the subsystems. For this reason, only the $\eta_{12}, \eta_{21}$ will be illustrated, according to Eq. (5). Fig. 7 represents these values for the Bended and Riveted $\left(90^{\circ}, 5\right.$ pts) cases. The results show that for both structures, the reciprocity assumption of the statistical energy analysis is fullfilled, because $\eta_{12}$ and $\eta_{21}$ are closely the same.

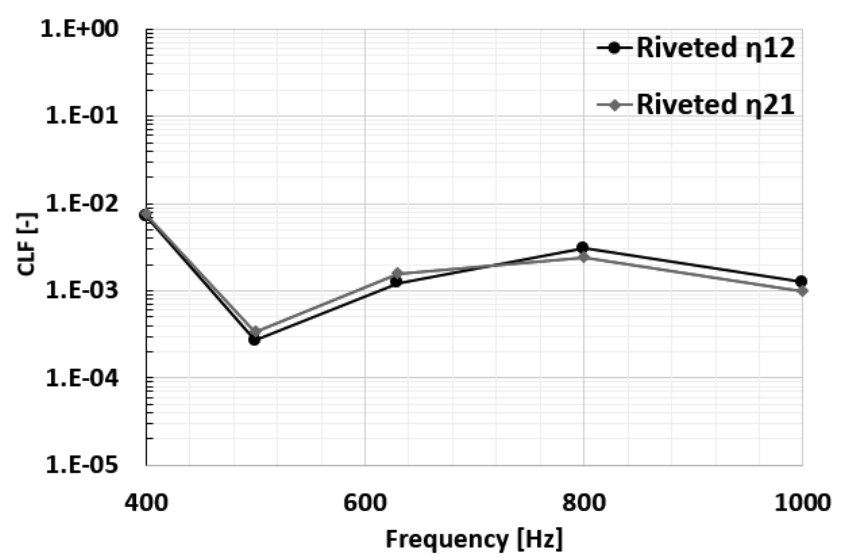

Fig. 7 Reciprocity of the Bended and Riveted structures (Number 1 and 7 case according to Tab. 1)

In the experiments, four load cases are applied, so both plates are excited 4 times in different locations. Fig. 8 shows the average CLF values of the 4 measurements, and its minimum and maximum values. As it can be seen, the range between the maximum and minimum values is decreased with increasing frequency. In the frequency range between $400-600 \mathrm{~Hz}$, there is more than two orders of magnitude difference between the maximum and minimum values, while around $1 \mathrm{kHz}$, this difference is less than one order of magnitude. This further emphasizes the well-known fact that SEA is better suited to high-frequency applications. As the frequency increases, the uncertanity of the measured values decreases. Thus during the simulations these parameters could be used with higher reliability at higher frequencies.

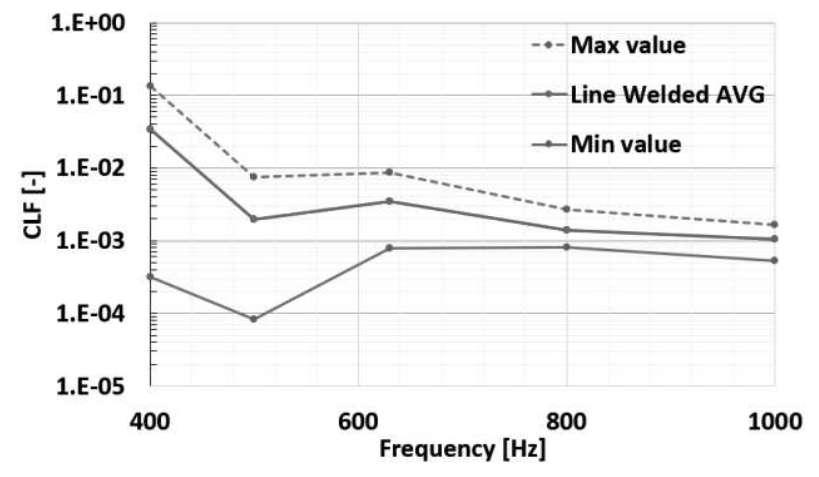

Fig. 8 The CLF average of four measurements of the Line welded joint and its minimum and maximum results in the frequency range. With increasing frequency, the deviation from the average value decreases. 
Fig. 9 shows the CLFs for different connection types for the right-angle configurations. For calrity, only a few bondig types are visualised. As can be observed, the Bended case (according to Tab. 1 Number 1 case) has the highest CLFs in this frequency range, with only the superglued structure exceeding this between the $400-500 \mathrm{~Hz}$ range. These two junction types have the highest CLFs from all junction types. Overall, the Point $W$ elded 5 pts structure has the highest energy loss at the connection, about one order of magnitude less compared to the Bended case. Below the 630 $\mathrm{Hz}$ band the Line Welded structure has lower coupling values than the Superglued structure. These results agree well with Panuszka's results [13], since the riveted structure had the highest CLF value compared to the bolted and point welded one. On the other hand, the spot-welded structure had the lowest CLF value. In this case, the values are closer to each other as well as overlapped in some bands, but in general, the same phenomenon can be seen. However, the bonding types overlap, and make it difficult to distinguish them. Mandale [9] observed similar results and the different connection types had close CLF values moreover in some band overlapped. Fig. 9 results show the importance of the determination of the individual connections and not only assumed as point or line types, furthermore these results can help to make a decision about an effective design of structures which joint is the most suitable in a particular vibrational condition.

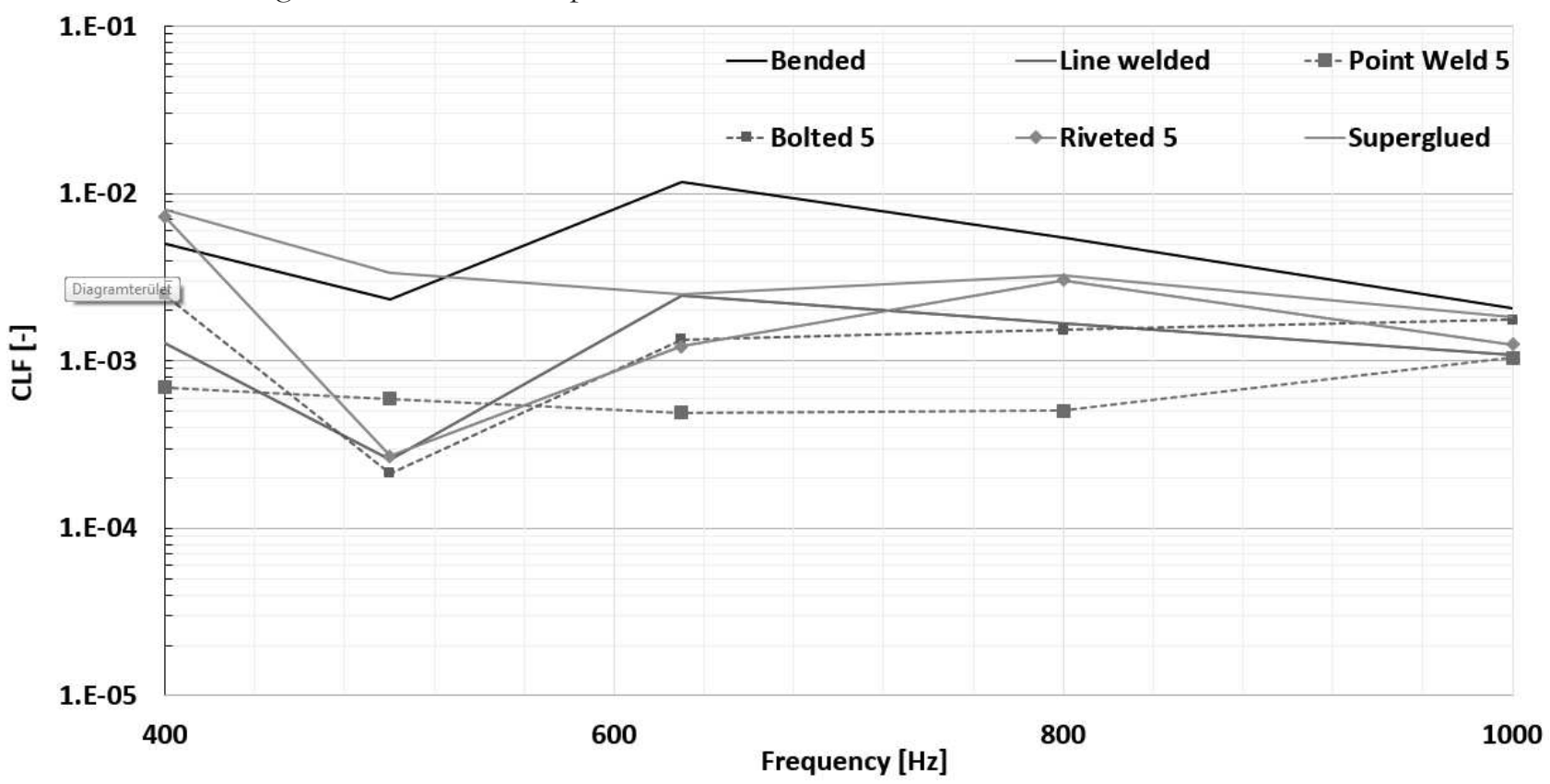

Fig. $9 C L F$ values of the right-angle structures obtained from measurements.

Fig. 10 shows the influence of the number of connection points on the value of CLFs. Two different layouts were investigated for the point welded and bolted structures: 5 points and 10 points spotwelding along the connection line, with $90 \mathrm{~mm}$ and $50 \mathrm{~mm}$ spacing, respectively. As can be seen, the difference between them is relatively small: in the point welded

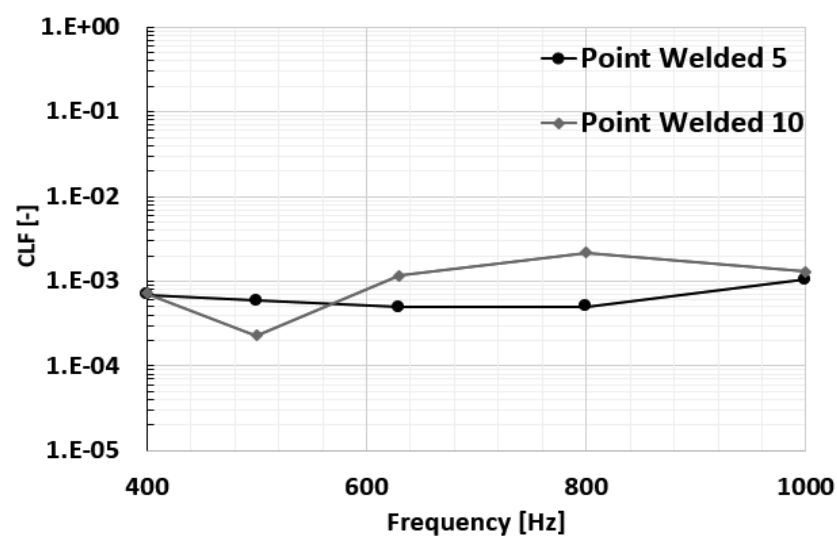

case the CLFs of the 10 points connection is clearly higher for most of the bands, while in the bolted case the difference is negligible. However the differences become more significant for the $400 \mathrm{~Hz}$ and $500 \mathrm{~Hz}$ bands, where the reliability of the measured CLF values is lower.

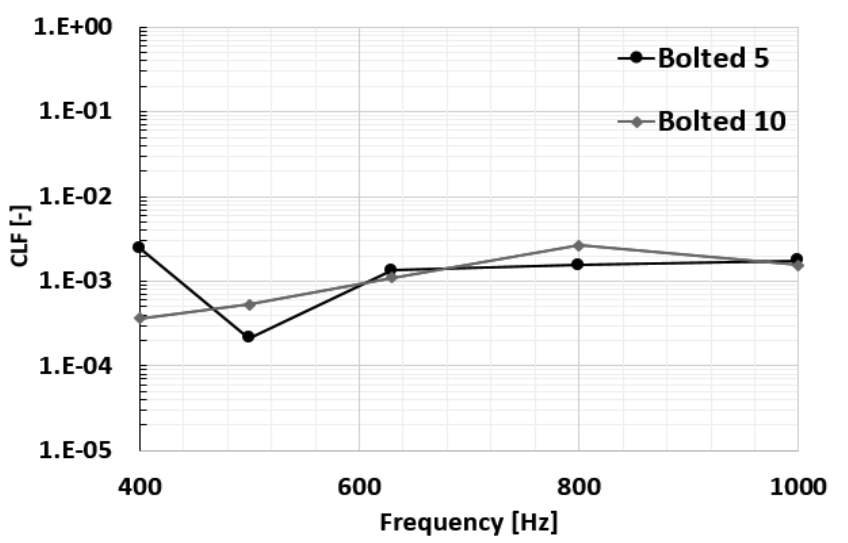

Fig. 10 The influence of the density of the points along the junction to the CLF value 
Fig. 11 depicts the change of the CLFs in terms of angle of the connected plates. In this case, the difference is more apparent and only in one frequency band is the CLF value higher for the right-angle Super-

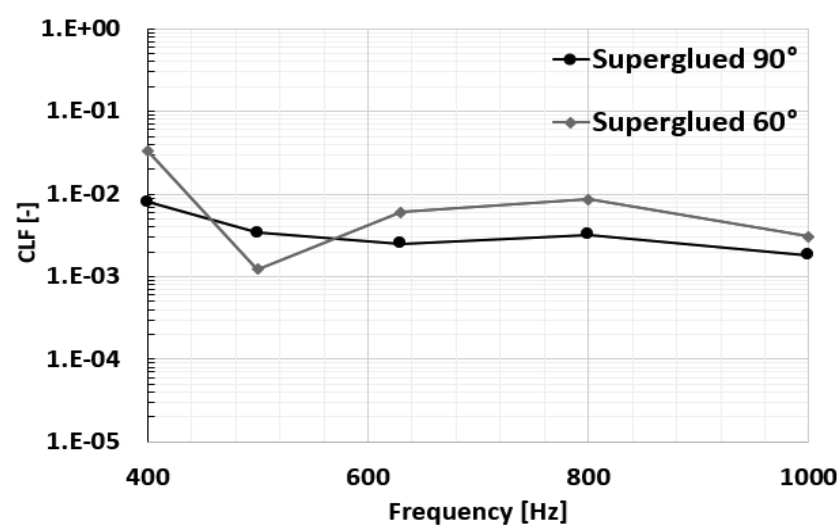

glued structure, than for the 60 degrees case. Consequently, it can be deduced that the smaller the connection angle, the larger the coupling value. That means, sharper connection angles lead to smaller energy loss between the subsystems.

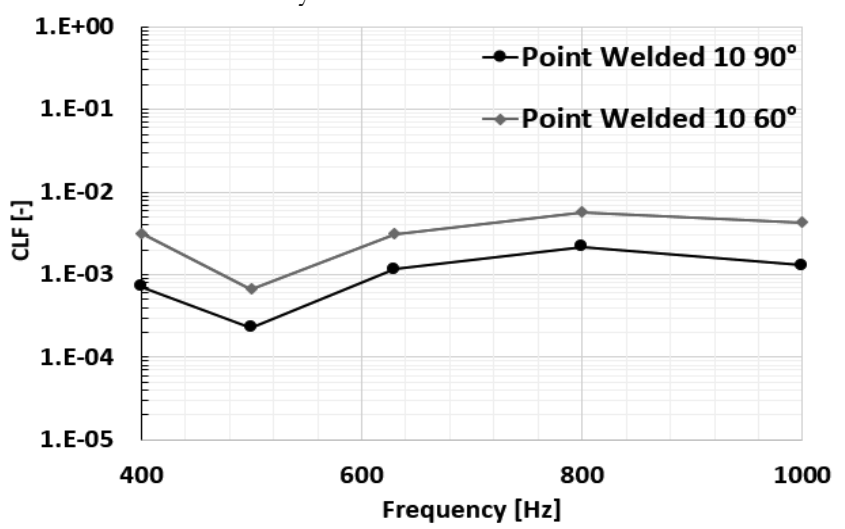

Fig. 11 The influence of the connection angle to the CLF value, two angles are measured: $90^{\circ}$ and $60^{\circ}$. Left side: superglued (Loctite 454), right side: point welded structure.

Fig. 12 illustrates the combined joints, such as simulataneous riveting and supergluing, as well as bolting and supergluing, with 5 and 10 connection points, respectively. Recall, that such combined sturctures were not investigated previously in the literature, so these results are quite unique. It is interesting to observe that the combined CLF values are neither the

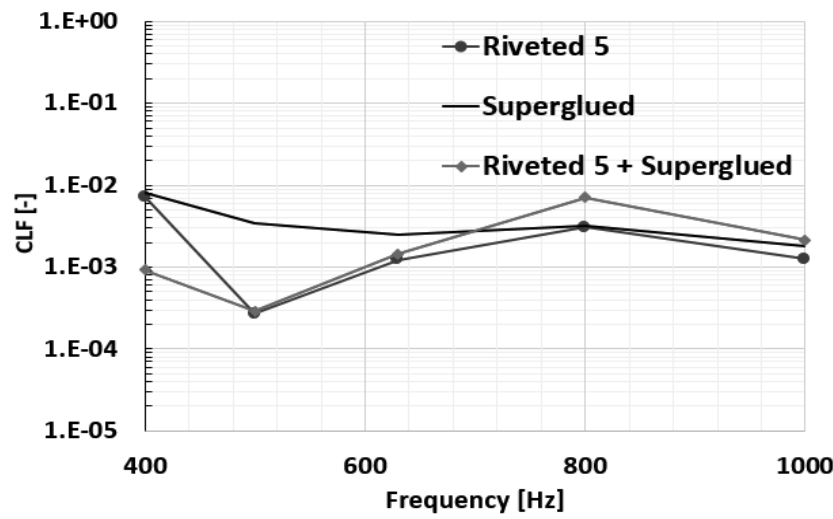

linear superposition of the individual values, nor do they match with the higher CLF connection (such as the superglued) in the whole frequency range. Rather, the combined junction CLFs are a mixture of the CLF values of the two individual junctions in both cases.

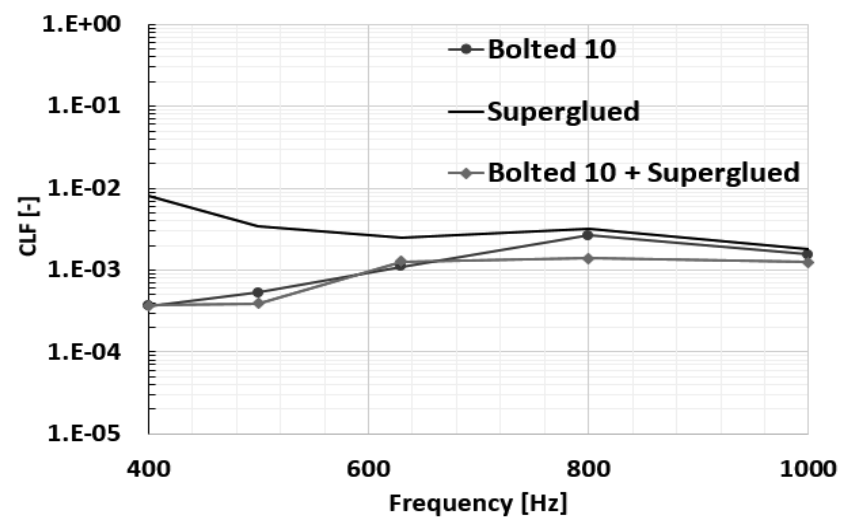

Fig. 12 CLF values of the combined joints and the individual joints. Both cases are right-angle configurations. Left side: riveted joints with $90 \mathrm{~mm}$ spacing combined with Loctite 454. Rigth side: bolted joint with $50 \mathrm{~mm}$ spacing combined with Loctite 454.

For the Superglued connection case, the structure is measured with three different thicknesses of Plate 2. This meant that not only a $2 \mathrm{~mm}$ thick plate is connected to Plate 1 , but also a $1.5 \mathrm{~mm}$ and $2.5 \mathrm{~mm}$ one as well. In this way, the effect of the thickness ratio of the connected plates can be examined. As Fig. 13 illustrates, the thickness ratio can cause notable differences in the CLFs, especially at the frequency range between 400-1000 Hz. As can be clearly seen, the case when the thickness of Plate 2 equals with Plate 1, the CLF has the highest value, while in other cases the CLF values are reduced. Note that these results are also uniqe, since to the knowledge of the authors, no prior literture has dealt with the comparison of varying connection plate thicknesses.

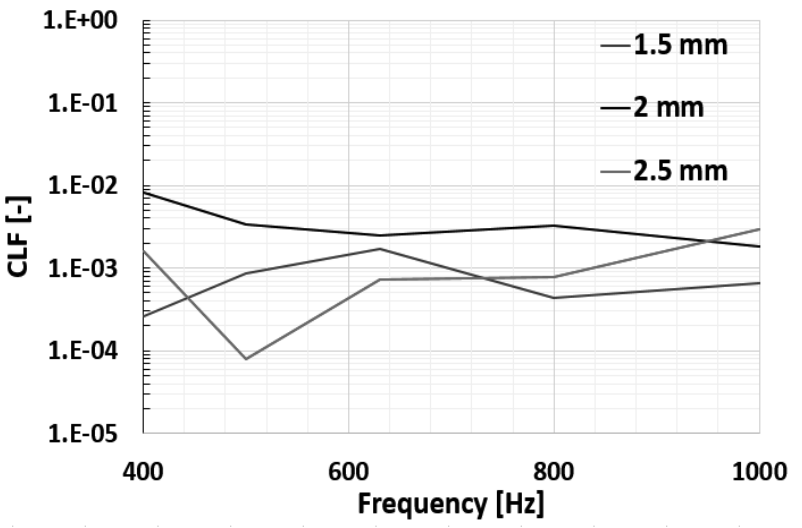

Fig. 13 Influence the thickness ratio of the connected plates to the CLF. 
The last comparison is shown in Fig. 14, where the different gluing techniques are compared. Superglue (Loctite 454) forms a very thin layer between the plates and creates a massive connection, while the Loctite 3450 is similar to the glues used in the vehicle industry: they create a thicker layer between the plates and also a massive connection. As the results show, the Loctite 454 has lower energy loss at the junction, while the Loctite 3450 has higher loss, probably due to the higher thickness as well as the higher flexibility of this glue. The Loctite 3450 is a better choice if the vibrational energy reduction is the main goal in a connected plate structure.

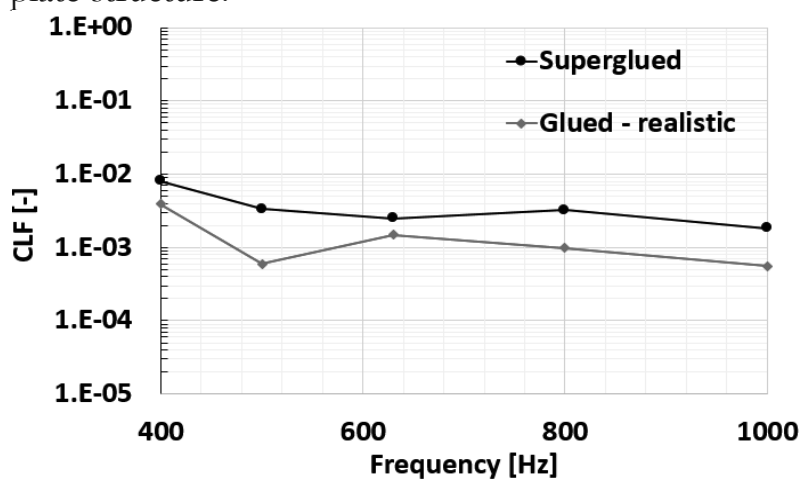

Fig. 14 Comparison of the CLFs of the two different glues

\section{Analytical coupling in SEA simulations}

The main advantage of using SEA simulations would be to apply them in the early stages of vehicle development, i.e. before prototyping takes place. However, SEA simulation results depend on several parameters, such as the DLF or CLF values. These parameters in experimental SEA come from the real structural measurements. This problem is contradictory, since in the early stage of the development neither a real structure nor a prototype is available to determine the required parameters. Therefore, in this section the validity of analytical CLF's will be investigated in the ESI VA One software. Three steps are applied to investigate the analytical coupling loss factors in the simulations and to reduce the role of the measurements, which are summarized in Table 2. The three steps differ in the way how the DLF values are determined, while extracting the CLF values from the analytical formulas in the VA One software. Note that in the $2^{\text {nd }}$ option, the DLF values come from a previous study of the authors [26], where a pure flat plate of the same size as Plate 1 and 2 is measured in uncoupled form.

Tab. 2 Different steps of investigation for examining the analytical coupling loss factors in SEA as well as to reduce the role of the measurements.

\begin{tabular}{|c|c|l|}
\hline Number of the step & Damping loss factor & Coupling loss factor \\
\hline 1 & From PIM measurement & From analytical formula in VA One \\
\hline 2 & From uncoupled flat plate & From analytical formula in VA One \\
\hline 3 & Set as a constant value & From analytical formula in VA One \\
\hline
\end{tabular}

All the simulations assume the same conditions, i.e. the geometry and material of the subsystems are set up just as for the real structure. The DLFs and CLFs are calculated from power injection method, and the excitation force was $1 \mathrm{~N}$. The comparison of the results was in the frequency range of 400-1600 Hz. The goal of this investigation was to examine that how to change the simulation results if the DLF or CLF values come from different sources? An additional goal was to examine that how accurate result are without any prior measurement?

\subsection{Line junctions}

When plate structures connect through a line junction, the CLF can be calculated in the following way:

$$
\eta_{i j}=\frac{k_{i} L_{c}}{2 \pi^{2} n_{i}(\omega) \omega}<\tau_{i j}>=\frac{c_{g i} L_{c}}{\omega \pi A_{i}}<\tau_{i j}>
$$

Where:

$c_{g i}$ is the group speed $[\mathrm{m} / \mathrm{s}]$,

$k_{i}$ wavenumber of waves in subsystem $i,[1 / \mathrm{m}]$,

$A_{i}$ is the area of the source subsystem $[\mathrm{m}]$,

$n_{i}(\omega)$ the modal density,

$L_{c}$ is the length of the junction [m], $<\tau_{i j}>$ is the diffuse transmission coefficient [-].

The relationship between the CLF and the transmission coefficient follows from the assumptions for energy and radiated power from the reverberant bending wave field on the source plate. Langley [23] derived this diffuse field transmission coefficient from plane-wave transmission theory:

$$
<\tau>=\frac{1}{2} \int_{0}^{\pi} \tau(\varphi) \sin \varphi d \varphi
$$

The transmission coefficient $\tau$ follows from the transmission and reflection of plane bending waves impinging with angle $\varphi$. There is no simple closed expression available that can be presented here, but it is important to quote the basic ideas and assumptions.

Langley assumes in his paper that the entering bending wave irradiates an infinite edge under angle $\varphi$ leading to a projected wavenumber $k_{x}$. The incoming wave is transmitted and reflected into a bending, a longitudinal and a shear wave. Thus, in general six transmission coefficients have to be considered. Because of the fact that the in-plane wave speeds are much higher than the bending wave speed the in-plane 
wave fields are not random and they are therefore neglected. Fig. 15 shows this phenomenon.

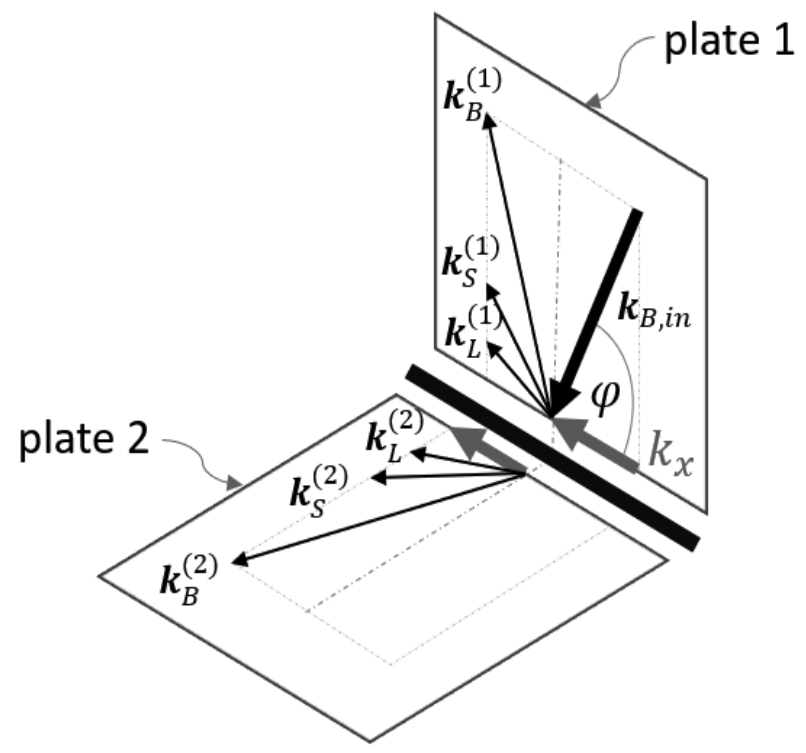

Fig. 15 Transmitted and reflected waves at the junction

In contrast to this, the calculation of the edge response requires the determination of the radiation stiffness of all wave-fields of both plates. The transmission coefficient follows finally from the power per length ratio of transmitted and incoming bending wave:

$$
\tau(\varphi)=\frac{\Pi_{\text {trans }}}{\Pi_{\text {in }}}[-],
$$

Note, that the angle of the transmitted wave can be different depending on the plate properties.

\subsection{Point junctions}

Langley presents in [24] the theory of wave transmission coefficients of point junctions. Similarly to the line junction theory, the transmission depends

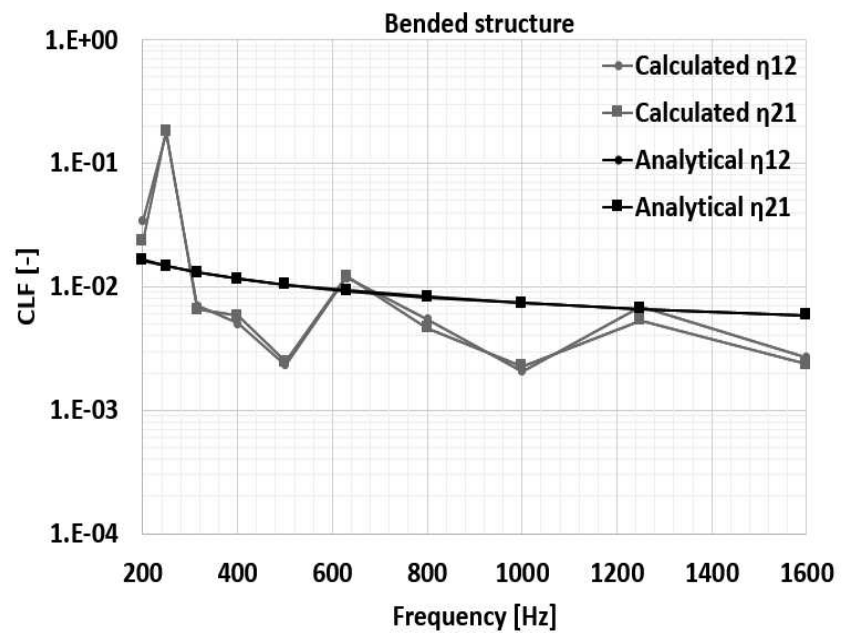

on the radiation stiffness of point connections and the specific wave field. The determination of the point radiation stiffness is defined in this paper for beams and point connections embedded in an infinite plate. The point connections at the edge would require a different point impedance, but this is not clearly defined in the software manual. The authors suppose that it is independent from point location and the plate point impedance is determined using a point connection embedded in an infinite plate.

Firstly, the results from Step 1 are introduced. Note that in this case the analytical CLF will be compared to the calculated CLFs from PIM. The DLFs are extracted in both cases by applying PIM to the experimental results. Fig. 15 illustrates the difference between the line and point junction modelling in the simulation software, while Fig. 16 represents the analytical CLFs and calculated CLFs from PIM for the Bended and Point Welded (5 pts, 90 ) structures.

As it can be seen, the analytical coupling values are quasi constants, while the calculated results are varying.

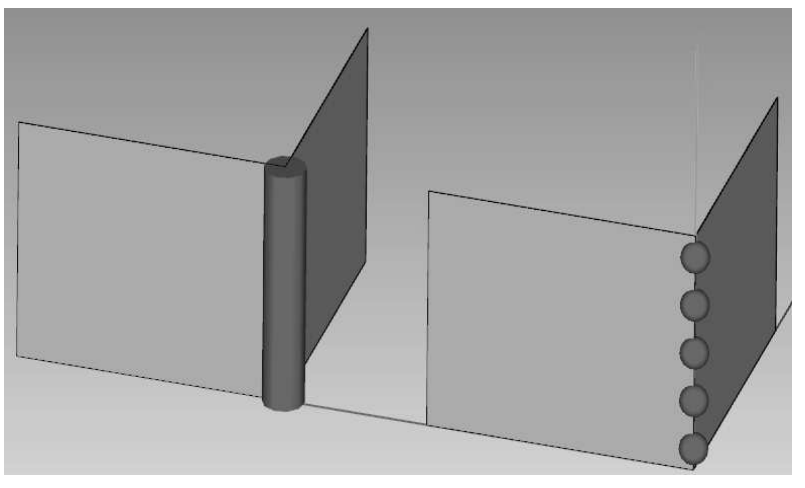

Fig. 15 Left side: line junction, right side: 5 points along the edge. The analytical coupling loss factor both of the junction types are investigated in the simulation software how accurate can be compare to the experiment results.

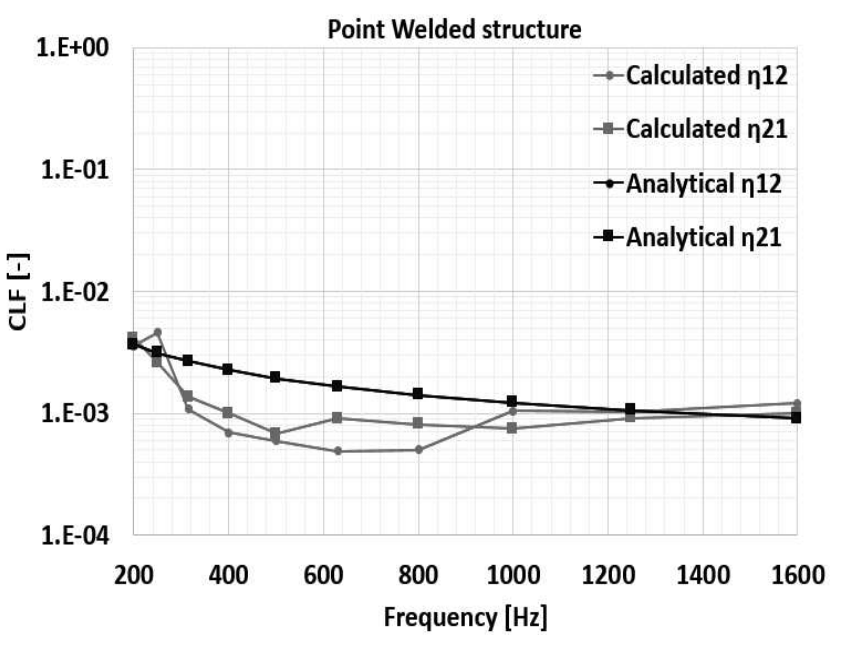

Fig. 16 The difference between the analytical CLFs and calculated CLFs from PIM. At the Bended structure, the analytical line junction is used, while at Point Welded case 5 points are used along the connection line, so analytical point junction is used. 


\section{Results and discussion}

At the Bended structure, where the plate is only bended and the connection is de facto perfect between the two subsystems, the analytical coupling loss factors worked quite well. In fact, they gave better results in some bands than the CLFs calculated from the PIM (see Fig. 17).

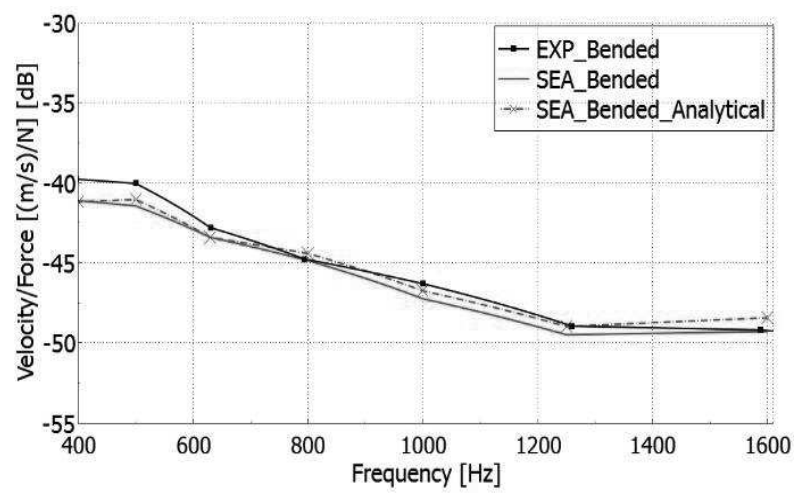

Fig. 17 Comparison of the Bended structure measurement and simulations results (Number 1 case according to $\mathbf{T a b}$. 1).

The Plate 1 is excited, the response is examined at Plate 2.

The solid, black curve is the experiment, the solid, red curve is the SEA result with the measured CLFs and DLFs values. The dashed, red curve with the crosses is the SEA result with the measured DLFs and the analytical CLFs which is calculated by the simulation software.

The Point $W$ elded $\left(5 \mathrm{pts}\right.$, $\left.90^{\circ}\right)$ results are very similar. In this case, the junction is not perfect, there are only 5 connection points along the line. As the diagram in Fig. 18 shows, the analytical point CLFs match the experiment results very well, moreover at lower frequencies the results are better compared to the measured values.

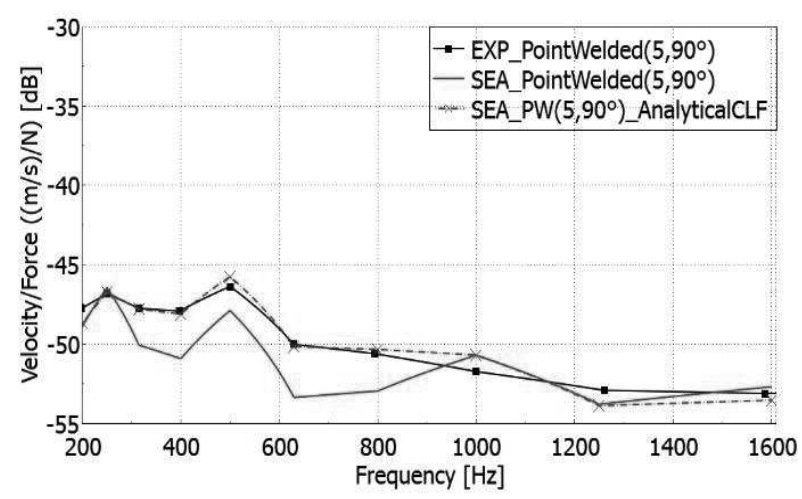

Fig. 18 Comparison of the Point welded structure measurement and simulations results (Number 3 case according to

Tab.1). The Plate 1 is excited, the response is examined at Plate 2. The solid, black curve is the experiment. The solid, red line is the SEA result with the measured CLFs and $D L F s$ values. The dashed, red line with the crosses is the

$S E A$ result with the measured DLFs and the CLFs are adjusted as analytical point junction in the simulation software with 5 points along the connction line (see Fig. 15 right).
Next, the results from Step 2 are introduced, by using results from a previous study by the authors [26]. In that work, the damping of an uncoupled flat plate was examined. In Step 2 simulations, these uncoupled plate DLFs are set to Plates 1 and 2, while the coupling data from the analytical formulas in VA One are applied. This example represents a case, in which one assumes that data for an isolated subsystem are available for all important measurement parameters (such as mass, damping, etc.) and another equivalent subsystem is connected to it. As the results shows in Fig. 19, the maximum deviation compared to the Bended structure measurement results in up to $3 \mathrm{~dB}$ difference, which although is not a perfect agreement, but in this situation it could be an acceptable deviation, since the simulation parameters came from an equivalent uncoupled subsystem results. The Point Welded (5 pts, 90 ) structure measurement result is also compared to the simulation where the uncoupled damping values with the 5 points analytical CLFs were adjusted. In this case, the maximum deviation is observed to be around $8.5 \mathrm{~dB}$ at $500 \mathrm{~Hz}$. That, however, is a huge deviation between the simulation and measurement and is likely caused by changing the connection type from an idealized line welding to a non-ideal point welding. This suggests, that for real connections, such as riveted, spot welded, etc. the approach of using measured damping of an equivalent, uncoupled subsystem might not be the right approach to achieve good simulation results. The analytical couplings are changed with the connection type, so in this case the only possibility to reach good accuracy with the simulations is to change the damping value with the connection types.

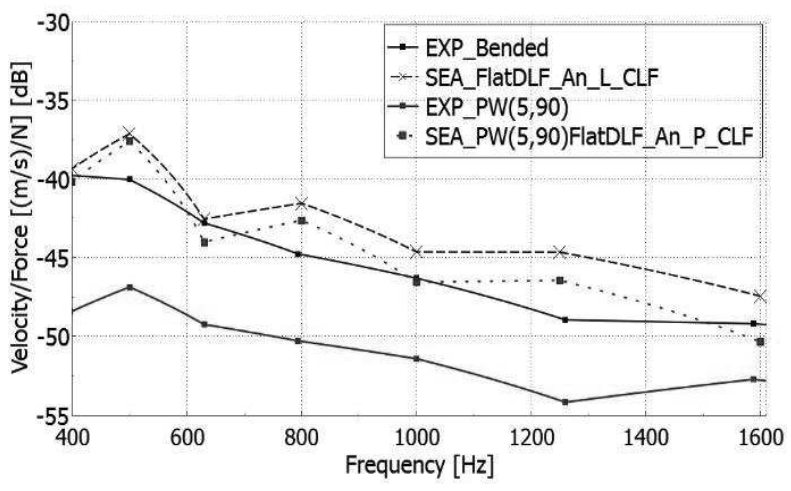

Fig. 19 Comparison of the experiment and simulation results. Plate 1 is excited and Plate 2 examined is measured. The solid, black curve is the Bended structure measurement result (Number 1 case according to Tab. 1), the blue, solid curve is the Point welded structure experiment results (Number 3 case according to Tab.1). Black, dashed curve with the crosses is the simulation results with the measured, uncoupled flat plate damping and analytical line coupling was calculated by the simulation software. The blue, dotted curve with the boxes is the simulation results with analytical point coupling was adjusted in the software and the damping was measured at uncoupled form. 
In SEA simulations, the results are highly influenced by the DLFs, as it was shown previously in Ref. 21. In complex structures, they also play an important role, since although the analytical coupling values could work well, they are independent of the damping values and therefore cannot take into consideration the different joint types, such as bolting, riveting or spot welding.

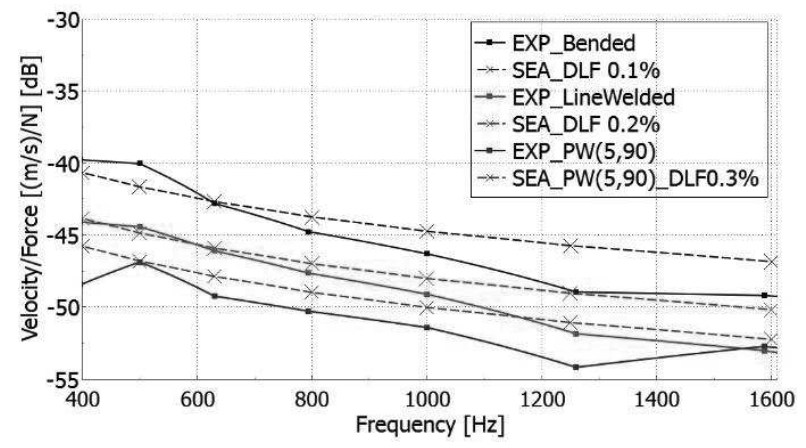

Fig. 20 Comparison of the different structures measurement and simulation results (Number 1, 2, 3 cases according to

Tab. 1). All case the Plate 1 is excited and the response is examined at Plate 2. The solid lines are the experiment results. The dashed lines are the SEA results with constant

$D L F s$ and analytical line CLFs are adjusted in the simulation software.

The last level of this study, Step 3 involved the strategy of applying the coupling values from analytical formulas, while the damping values are set to constant values, despite the damping of real structures not being constant over a certain frequency range. Thus,
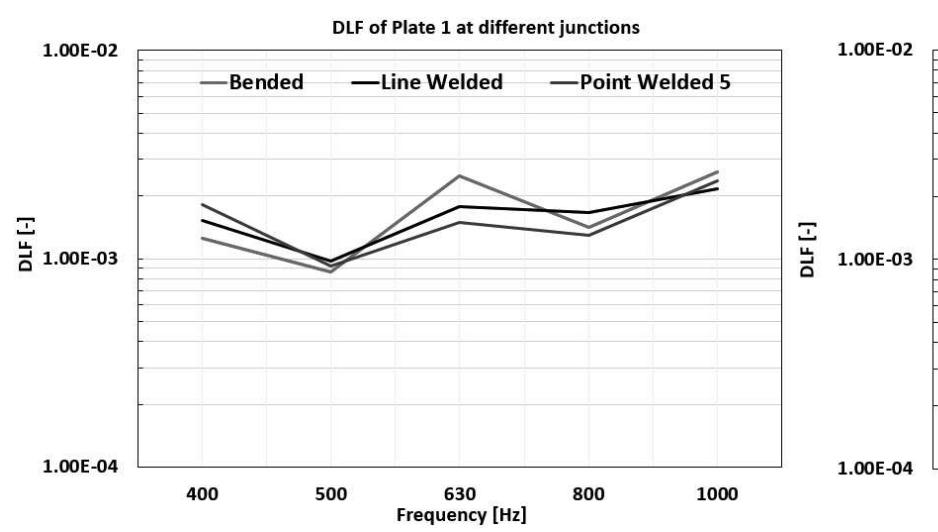

Fig. 22 The changing of the Plate DLFs in terms of the different junction type

As a summary, the results showed that in the midfrequency range these values are varying due to the fact that the various joints are overlapped, and they did not separate from each other clearly. The Bended and Superglued structures had the highest coupling values while the Point Welded the lowest ones.

The simulation results agreed well with the experiment, when the DLFs and CLFs parameters came from the PIM. The study partly focused on decreasing the damping was set to $0.1 \%$ for the Bended structure, which is a commonly used value for such steel plates. As the comparison in Fig. 20 shows, the DLF values were again not perfect, but even so the maximum deviation between the experiments and simulations were only around $3 \mathrm{~dB}$ at $1250 \mathrm{~Hz}$ band without any measurements.

As Fig. 19 and Fig. 20 show, the analytical couplings varied slightly as a function of the different connections e. g. point welding, line welding, no junction, but the extent of this is not enough to achieve the experimental results. Consequently, the damping must be changed to the different structures in order to estimate the experiments.

At this type of plate connection, Plate 1 is curved to implement the connection of Plate 2, which is flat as can be seen in Fig. 5. As a result of the curvature of Plate 1, the damping just slightly changes when the connection types are varied at this subsystem, while the damping of Plate 2 depends more on the connection type. An interesting phenomenon can be observed for the damping of Plate 2: as the junction type deviates from the perfect connection (Bended plates), the damping value is increased. Thus the damping of the Point welded structure is increased by a factor of about three compared to the Bended structure. As can be seen in Fig. 22, Plate 2 varies with the junction type, while Plate 1 damping remains similar regardless of the junction. According to this phenomenon a proper junction could effectively increase the damping of the Plate 2, as if using damping foil and added extra mass to the structure.

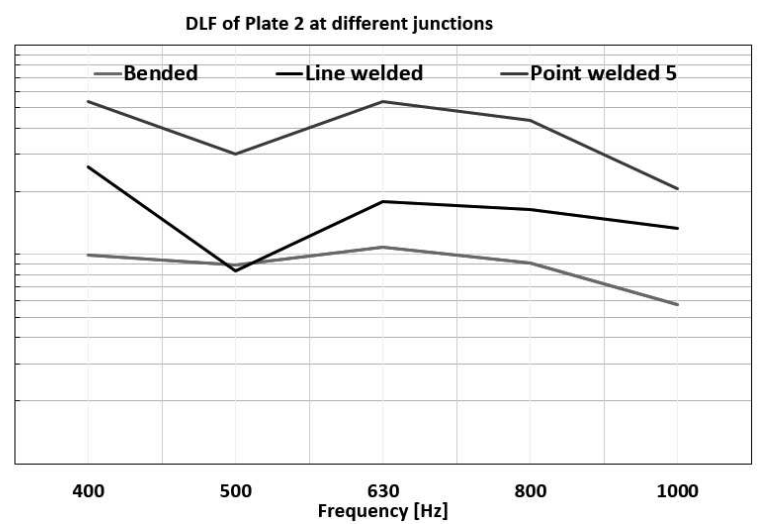

the role of the experiments in the simulation parameters determination. For this reason, the DLFs remained the measured values, while in the simulation software the analytical couplings are adjusted. This proved to be a good option in the case when no measurement data for the CLFs is available. At junctions, such as Bended, Glued, Combined or Line welded structures, then the analytical line junction is the good setting. When the plates are connected along points, such as Riveted, Bolted or Spot welded then the analytical point coupling 
is the right setting. These analytical formulas in some case could give a better result as the measured values.

In the case, when the damping is measured for an uncoupled subsystem, such as the pure flat plate, and analytical coupling is adjusted at the junctions, the results did not fit well with the experiments, especially when any real connection occurs between the plates. The results are satisfying only at the Bended structure.

It is difficult to determine the parameters, such as the DLF or CLF values without any measurements. In some cases, the constant damping and analytical coupling values could be a good solution, when the measurement is not possible. For a flat, steel plate, the $0.1 \%$ damping loss factor is reasonable, and combined with the analytical coupling loss factor in VA One at the junction has led to quite good results if there is no physical joint between the subsystems, for instance in the Bended case. The situation was different when the structure contained some real junction, because the response highly depended on the damping value of the plates and this in turn depended on the type of the junction.

\section{Conclusions}

This study examined the importance of the damping and coupling loss factors for the vibroacustic behaviour of a system of two plates, connected with various junction types typical of modern vehicle structures. The main conclusions of the investigation are the following:

- In the investigated frequency range (400 $1000 \mathrm{~Hz}$ ) the CLF values are varying. At lower frequencies, the deviation between minimum and maximum values can reach more than 2 orders of magnitude.

- The Bended and Superglued structures had the highest coupling values while the Point Welded the lowest ones.

- The CLF values increased proportionally with the number of connection points, while the CLF values decreased with increasing connection angle.

- In the combined joint cases, the CLFs could not be clearly defined: it was a mixture of the properties of the two base joints and they were in the same order of magnitude as the base joints.

- The results of the two different glue types is obvious: the Loctite 3450 had lower coupling loss in all frequency bands, which means higher energy loss on it.
The second part of the paper deals with the Statistical Energy Analysis simulations and their comparison to measurements. In addition, it examined the possibility of the reducing the role of the measurements, so the measured parameters were compared to the analytical results. The conlusions and interesting observations this part of the study were the following:

- The simulation results agreed well with the experiment, when the DLFs and CLFs came from the measurement.

- In the case, when the DLF was measured and the CLF was applied from analytical formulas: the simulation results showed good agreement with the experimental results, so it could be a good option in the case when no measurement data for the CLFs is available.

- In the case, when the damping was measured for an uncoupled subsystem, such as the pure flat plate, and the CLF was adjusted as analytical, the results did not fit well with the experiments, especially when any real connection occured between the plates.

- In the case, when a constant damping and analytical coupling loss factors were combined, that has led to quite good results if there is no physical joint between the subsystems, for instance in the Bended case. The $0.1 \%$ damping loss factor could be reasonable for such a steel plates, but these parameters worked well only in the Bended structure case. The situation was different when the structure contained some real junction. In this case, the interesting observation was that the type of the connection have changed not only the coupling values, but the damping value of the plates as well. The outcomes showed that most of the bond types can be describe well with the analyctical couplings, but the damping of the plates could be also determined somehow without measurements. The main issue is how can one describe the damping level variation as a function of the different connection types. Of course, in this study the damping values were available, but when they were not, for instance at the early stage of the development, when no prototype or real structure is available, the measurement of the damping values is not an option. In this case, the function of the damping changing in 
terms of the bonding type could be crucial. The study of this phenomena is one of the main goals for the future work.

\section{Acknowledgements}

This work is supported by the Hungarian Academy of Sciences and Audi Hungaria Zrt. through the funding provided to the MTA-SZE Lendület Vehicle Acoustics Research Group.

\section{References}

[1] LYON, R. H., DEJONG, R. G. (1995). Theory and Application of Statistical Energy Analysis, Butterworth-Heinemann, Second Edition

[2] VAŠINA M, HRUŽÍK L, BUREČEK A. (2020) Study of Factors Affecting Vibration Damping Properties of Multilayer Composite Structures, Manufacturing Technology, Vol. 20, No. 1, pp. 104-109. DOI: $10.21062 / \mathrm{mft} .2020 .019$.

[3] KOVÁČIKOVÁ P, DUBEC A, VAVRO J. (2019) Comparison of Damping Effects of Two Types of Graphite Cast Iron, Manufacturing Technology, Vol. 19, No. 5, pp. 792-796. DOI: $10.21062 /$ ujep/373.2019/a/12132489/MT/19/5/792

[4] GU, J., SHENG, M. (2015.) Improved Energy Ratio Method to Estimate Coupling Loss Factors for Series Coupled Structure, Journal of Mechanical Engineering, Vol. 45, No. 1, pp. 37-40.

[5] BOUHAJ, M., ESTORFF, O., PEIFFER, A. (2017). An approach for the assessment of the statistical aspects of the SEA coupling loss factors and the vibrational energy transmission in complex aircraft structures: Experimental investigation and methods benchmark, Journal of Sound and Vibration, 403: pp. 152-172. DOI: http://dx.doi.org/10.1016/j.jsv.2017.05.028

[6] JAMES P. P., FAHY, F. J. (1997). A technique for the assessment of strength of coupling between SEA subsystem: experiments with two coupled plates and two coupled rooms, Journal of Sound and Vibration, 203: pp. 401-407.

[7] BIES, D. A., HAMID, S. (1980). In situ determination of loss and coupling loss factors by the power injection method, Journal of Sound and Vibration, 70: pp. 187-204.

[8] SABLIK, M. J. (1982). Coupling Loss Factors at a beam L-joint revisited, Journal of Acoustic Society of America, Vol. 72, No. 4, pp. 1285-1288.

[9] MANDALE, B. M., BABU, P. B., SAWANT, S. M. (2016). Statistical energy analysis parameter estimation for different structural junctions of rectangular plates, Journal of Mechanical Engineering Science, Vol. 230, No. 15, pp. 2603-2610. DOI: $10.1177 / 0954406215615628$

[10] MANDALE, B. M., POPURI, B. (2019). Estimation of coupling loss factors for rectangular plates with different materials and junctions, Noise \& Vibration Worldwide, 50(9-11), pp. 306312. DOI: $10.1177 / 0957456519883264$

[11] LE BOT, et al. (2017). Statistical Energy Analysis, Assumptions and Validity, Medyna 2017: 2nd Euro-Mediterranean Conference on Structural Dynamics and Vibroacoutics, Sevilla, Spain, 25-27 Apr.

[12] PATIL, V. H., MANIK, D. N. (2019). Sensitivity analysis of a two-plate coupled system in the statistical energy analysis (SEA) framework, Springer, Structural and Multidisciplinary Optimization, 59: pp. 201-228. DOI: https://doi.org/10.1007/s00158-018-2061-9

[13] PANUSZKA, R., WICIAK, J., IWANIEC, M. (2005). Experimental Assessment of Coupling Loss Factors of Thin Rectangular Plates, Archives of Acoustics, Vol. 30, No. 4, pp. 533551.

[14] BOSMANS, MEES, P., VERMEIR, G. (1996). Structure-borne sound transmission between thin orthotropic plates: analytical solutions, Journal of Sound and Vibration, Vol. 191, No. 1, pp. $75-90$.

[15] CUSCHIERI, M., SUN, J. C. (1994). Use of Statistical Energy Analysis for Rotating Machinery: Determination of Dissipation and Coupling Loss Factors Using Energy Ratios, Journal of Sound and Vibration, Vol. 170, No. 2, pp. 181-190.

[16] WESTER, E. C. N., MACE, B. R. (1996). Statistical Energy Analysis of Two Edge-Coupled Rectangular Plates: Ensemble Averages, Journal of Sound and Vibration, Vol. 193, No. 4, pp. 793 822.

[17] WÖHLE, W., BECKMANN, Th., SCHRECKENBACH, H. (1981). Coupling Loss Factors for Statistical Energy Analysis of Sound Transmission at Rectangular Structural Slab Joints, Part I., Journal of Sound and Vibration, Vol. 77, No. 3, pp. 323-334.

[18] WÖHLE, W., BECKMANN, Th., SCHRECKENBACH, H. (1981). Coupling Loss Factors for Statistical Energy Analysis of Sound Transmission at Rectangular Structural Slab Joints, Part II., Journal of Sound and Vibration, Vol. 77, No. 3, pp. 335-344. 
[19] DESMET, W., et al. (2012). "MIDFREQUENCY" - CAE Methodologies for MidFrequency Analysis in Vibration and Acoustics, ISBN 978-94-6018-523-6

[20] MECAS ESI Group, (2018). VA One Users' Guide

[21] HENKEL. (2012). „ Technical Data Sheet of Loctite ${ }^{\circledR}$ 454 ${ }^{\mathrm{TM}} "$ [Revised Nov. 2020] http://tds.henkel.com/tds5/Studio/ShowPDF $/ 243 \% 20$ NEW-EN?pid=454$2012 \% 20$ NEW \&format $=$ MTR\&subformat $=\mathrm{R}$ EAC\&language $=E N \&$ plant $=$ WERCS

[22] HENKEL. (2014). „, Technical Data Sheet of Loctite ${ }^{\circledR}$ EA 3450"TM" [Revised Nov. 2020] http://tds.henkel.com/tds5/Studio/ShowPDF/243\%20NEWEN?pid $=$ EA $\% 203450 \&$ format $=$ MTR\&subfor mat $=$ REAC\&language $=E N \&$ plant $=$ WERCS

[23] LANGLEY R. S., HERON, K. H. (1990). Elastic wave transmission through plate/beam junctions, Journal of Sound and Vibration, Vol. 143, No. 2, pp. 241-253.
[24] LANGLEY R. S., SHORTER, P. J. (2003). The wave transmission coefficients and coupling loss factors of point connected structures, The Journal of the Acoustical Society of America, Vol. 113, No. 4, pp. 1947-1964.

[25] FREDÖ, C. R. (1999). A Note on Conservative and Non-conservative Coupling, in F. J. Faby, W. G. Price (eds), IUTAM Symposium on Statistical Energy Analysis, Solid Mechanics and Its Applications, vol 67. Springer, Dordrecht, pp. 95-106. ISBN: $\quad 978-90-481-5131-8 D O I:$ https://doi.org/10.1007/978-94-015-91737_9

[26] TRESZKAI, M. F., SIPOS, D., FESZTY, D. (2020). Damping Determination by HalfPower Bandwidth Method for a Slightly Damped Rectangular Steel Plate in the Mid-Frequency Range, Acta Technica Jaurinensis, Vol. 13, No. 3, pp. 177-196. DOI: 10.14513/actatechjaur.v13.n3.545 